\title{
Phytopathology
}

\section{Marker-Assisted Selection for Disease Resistance in Wheat and Barley Breeding}

\author{
Thomas Miedaner and Viktor Korzun
}

First author: T. Miedaner, State Plant Breeding Institute, Universität Hohenheim, Fruwirthstr. 21, 70599 Stuttgart, Germany; second author: V. Korzun, KWS LOCHOW GMBH, 29303 Bergen, Germany. Accepted for publication 30 January 2012.

\begin{abstract}
Miedaner, T., and Korzun, V. 2012. Marker-assisted selection for disease resistance in wheat and barley breeding. Phytopathology 102:560-566.
\end{abstract}

Marker-assisted selection (MAS) provides opportunities for enhancing the response from selection because molecular markers can be applied at the seedling stage, with high precision and reductions in cost. About each of 50 genes conferring monogenic resistances and hundreds of quantitative trait loci (QTL) for quantitative disease resistances have been reported in wheat and barley. For detecting single-major gene resistance, MAS could be easily applied, but is often not necessary because the resistances are selected phenotypically. In quantitative disease resistances, MAS would be very useful, but the individual QTL often have small effects. Additionally, only a few monogenic resistances are durable and only a few QTL with high effects have been successfully transferred into elite breeding material. Further economic and biological constraints, e.g., a low return of investment in small-grain cereal breeding, lack of diagnostic markers, and the prevalence of QTLbackground effects, hinder the broad implementation of MAS. Examples in which MAS has been successfully applied to practical breeding are the wheat rust resistance genes Lr34 and Yr36, the eyespot resistance gene $P c h l$, the recessive resistance genes rym $4 /$ rym5 to barley yellow mosaic viruses, mlo to barley powdery mildew, and two QTL for resistance to Fusarium head blight in wheat (Fhbl and Qfhs.ifa-5A). Newly identified broad-spectrum resistance genes/QTL conferring resistance to multiple taxa of pathogens offer additional perspectives for MAS. In the future, chip-based, highthroughput genotyping platforms and the introduction of genomic selection will reduce the current problems of integrating MAS in practical breeding programs and open new avenues for a molecularbased resistance breeding.

Additional keywords: Barley yellow mosaic virus complex, biotrophs, durable resistance, marker-assisted backcrossing.

Corresponding author: T. Miedaner; E-mail address: miedaner@uni-hohenheim.de

http://dx.doi.org/10.1094/PHYTO-05-11-0157

This article is in the public domain and not copyrightable. It may be freely reprinted with customary crediting of the source. The American Phytopathological Society, 2012
Disease resistance is an important trait in public and commercial plant breeding. For each breeder, it is a critical decision for which diseases resistance selection should be performed because each additional trait reduces selection intensity for all other traits given a fixed population size or requires a higher budget. This decision is governed by the yield losses that are caused by the disease, the importance to the farmer, the alternative measures for disease control, the availability of resistance sources, their durability (definitions, see Box 1) and the input needed for selection. Molecular markers might stimulate selection gain because they can be assessed in high-throughput techniques at a very early growth stage with high heritability and they are relatively cheap since the advance of single-nucleotide polymorphism (SNP) detection platforms. Besides technical questions, the availability of markers with a linkage as close as possible to genes of high impact, ideally based on the gene sequence ("perfect marker"), is the most critical point for successful marker-assisted selection (MAS) and/or marker-assisted backcrossing (MABC).

\section{WHAT IS AVAILABLE? - A BIOLOGICAL POINT OF VIEW}

Disease resistances can generally be divided into qualitative and quantitative resistances (Box 2). From an epidemiological point of view, qualitative resistances act against some races (racespecific, vertical), whereas quantitative resistances are similarly effective against all races of a pathogen (non-race-specific, horizontal; 37). Genetic analysis of progenies from crosses between resistant and susceptible parents reveal either a qualitative, discontinuous distribution of infection type (mono-/digenic inheritance according to the segregation ratio) or a quantitative, continuous distribution of disease severity (oligo-/polygenic inheritance). The latter is also called partial resistance by some authors (26). It should be noted that this simple classification scheme does not fully reflect nature's complexity and exceptions frequently occur. Qualitative resistances often involve a hypersensitive reaction governing a very high level of resistance, sometimes even a complete resistance. They are easy to handle for the breeder, can often be assessed in seedling stage, but are prone to lose their effectiveness by rapid changes in pathogen populations. Numerous markers of different types are available for many 
wheat and barley diseases, including viruses, fungi, insects, and nematodes (17) plus additional markers and mapped genes identified during the past decade. To date, each of about 50 genes could be routinely used for MAS in wheat and barley breeding programs (described below). The main question that remains is whether these genes will be durable.

Quantitative resistances are inherited by several genes with minor effects being dependent on nongenetic effects, like host growth stage, host organ, and environment (12). They can in practice only be selected in the respective plant stage in the field across several environments (locations, years) and molecular markers should be a great benefit for selection. Markers linked to the genes that underlie a quantitative trait are designated as quantitative trait loci (QTL, further definitions see Box 3). Numerous studies, however, have shown that many quantitative resistances are conditioned by a great number of QTL with small effects. Analyzing 85 QTL studies of 18 crops, Kover and Caicedo (18) found an average of 4.6 QTL per pathosystem with a range from 0 to 18 . An individual QTL explained on average about $20 \%$ of phenotypic variance and the range was 0 to $87 \%$, where the high values may refer to monogenic resistances with partial effects. In conclusion, for MAS to be feasible, the QTL should explain at least between 10 and $20 \%$ of phenotypic variance in the original mapping population. Modern mapping approaches including new types of plant populations and recently developed biometrical tools, like joint linkage association mapping or nested association mapping, will stimulate detection of further QTL that might be more independent of genetic background.

\section{WHAT IS COMMERCIALLY FEASIBLE? - AN ECONOMICAL POINT OF VIEW}

In North America most wheat and barley breeding programs are run in public institutions, whereas in Europe they are practiced by private companies and financed by royalties from the farmers who buy seed. Therefore, economical features might be in Europe of higher importance for assessing MAS than in the United States or Canada. The relatively low economic margin for breeders of selfpollinating crops might be one cause why they have been relatively reluctant to incorporate MAS to date. In contrast, the private-sector breeding companies have done major investments in MAS infrastructure and intensively use it in breeding of maize (17) and of several other hybrid crops, including sunflower and sugar beet.

Economic constraints cover not only costs of genotyping, but also questions of how to integrate MAS effectively into commercial breeding programs to enhance the gain from selection (20). MAS provides no advantage for monogenic resistances already expressed in the seedling stage that can be easily selected in seedling or by detached-leaf segment tests. For monogenic, adult-plant resistance governing durable resistance, it should be advantageous to select the respective resistance alleles using markers already in a very early stage of selection. But it should be noted that such a fixation of whole breeding programs for individual major genes will provide an extremely high selection pressure to the pathogen that might endanger even genes previously thought to be durable. Additionally, the genomic region where the gene is located will also be fixed, preventing the selec-

\section{BOX 1}

Definitions of terms for disease resistance as used in this paper

\begin{tabular}{|c|c|}
\hline Adult-plant resistance & $\begin{array}{l}\text { Resistance only visible in the adult stage of a plant, i.e., at the generative phase (contrast } \\
\text { seedling resistance). Adult-plant resistance can be inherited mono- or oligogenically. Adult-plant } \\
\text { resistance need not be durable. }\end{array}$ \\
\hline Broad-spectrum resistance locus/QTL & $\begin{array}{l}\text { Individual locus/QTL that confers resistance to multiple races of a pathogen species or multiple } \\
\text { taxa of pathogens. }\end{array}$ \\
\hline Durable resistance & $\begin{array}{l}\text { Resistance that remains effective for a long period when applied on a large scale in a region } \\
\text { that is undergoing regular epidemics of the pathogen (16). }\end{array}$ \\
\hline Epistasis & Interaction between genes at different loci. \\
\hline Partial resistance & $\begin{array}{l}\text { Resistance locus/QTL that do not provide a complete resistance irrespective of the mode of its } \\
\text { inheritance. QTL are always partially expressed, but some monogenically inherited resistance } \\
\text { genes also show partial expression, e.g., Lr34, Yr36, and Pch1. The term partial resistance, } \\
\text { often used synonymously with quantitative resistance, is therefore ambiguous. }\end{array}$ \\
\hline Pathosystem & $\begin{array}{l}\text { Combination of a specific host and pathogen species or a complex of closely related pathogen } \\
\text { species. }\end{array}$ \\
\hline Race & $\begin{array}{l}\text { Genotypes within a pathogen species that are distinguishable by their virulence, e.g., all yellow } \\
\text { rust isolates infecting wheat genotypes with the resistance gene Yr17 belong to the same } \\
\text { race. Races mostly are a complex combination of virulences, thus 'pathotype' might be a } \\
\text { better term. }\end{array}$ \\
\hline Qualitative resistance & $\begin{array}{l}\text { Race-specific, monogenically inherited resistance (Box 2), also named vertical resistance (37) or } \\
\text { hypersensitivity resistance (26) although not all resistance genes show this phenotype, e.g., } \\
\text { Lr34. }\end{array}$ \\
\hline Quantitative resistance & $\begin{array}{l}\text { Resistance inherited by several genes with minor effects (Box 2), usually non-race-specific and } \\
\text { prone to nongenetic interactions, also named horizontal resistance (37). }\end{array}$ \\
\hline
\end{tabular}


tion of economically important genes/QTL of that region that are not present in the resistance donor. Simulation studies showed that the introgressed region might span as much as $32 \mathrm{cM}$ in the sixth backcross generation when the gene of interest is in the middle of the chromosome (32). This is even more problematic when pyramiding several resistance genes.

Most experiments on QTL detection in cereals allow only the estimation of wide chromosomal regions of 10 to $20 \mathrm{cM}$ due to restricted population sizes. Further validation in independent populations, especially in elite material, is subsequently required to assure the use of the contributing QTL and their markers in practice. Often there is a lack of consistency of the effect of the same QTL between populations and studies, caused by QTLgenetic background (epistasis, linkage) or QTL-by-environment interactions.

In breeding practice, selection using QTL is more complex than phenotypic selection alone. Issues such as reduction of selec- tion intensities and relative emphasis given to each trait make optimal selection more difficult, with a need for using adequate relative weights of the introgressed QTL and considering the genotypic portions of the total variance for each trait at each generation.

The genetic constraints of MAS from a practical point of view are at present: (i) the restricted availability of "diagnostic markers", i.e., markers that could be used in multiple genetic backgrounds, (ii) the fixation of large genomic regions by selecting several genes/QTL located, e.g., on the same arm of the chromosome, and (iii) linkage drag, i.e., unwanted effects of the introgressed QTL for other agronomically important traits, e.g., yield penalty.

At the current stage of MAS in small-grain cereal breeding, markers should not be viewed as a complete replacement for conventional selection techniques, especially due to the high number and the genetic complexity of the selected traits. It must be noted

BOX 2

The concept of qualitative and quantitative resistance. Terminology in resistance research is inconsistent because of the use of terms from different scientific backgrounds. Van der Plank (37) coined the epidemiological terms 'vertical resistance' and 'horizontal resistance' by confronting several races of Phytophthora infestans with different cultivars. Variety A, incorporating resistance gene 1, is resistant only to those races that do not possess the matching virulence 1 (=race-specific resistance, vertical resistance). Variety B is resistant to all races (=non-race-specific resistance, horizontal resistance). The genetic basis of resistance can be analyzed by crossing a resistant with a susceptible parent and infecting the segregating progenies with the pathogen. This takes three generations (parental, $F_{1}$ generation, and $F_{2}$ generation/double-haploid lines). If only one gene with full expression is responsible for the resistance and no environmental effects occur, a qualitative segregation will appear. The 3:1 segregation ratio from the example indicates a monogenic-dominant inheritance $(1=$ incompatible, 6 = fully compatible). When disease resistance is inherited in a more complex manner (oligo- or polygenically), the outcome of a progeny test will be quantitative, i.e., a continuous distribution from low to high disease severity resembling a normal (Gaussian) distribution ( 1 = healthy, 9 = fully diseased $)$.

\section{A Qualitative Resistance (Variety A) B Quantitative Resistance (Variety B)}

\section{In epidemiological terms: vertical vs. horizontal}
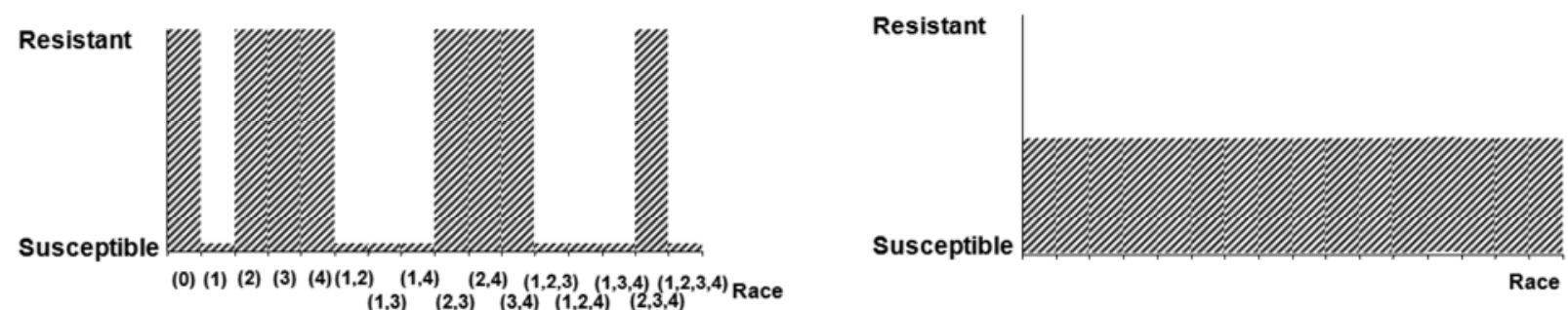

\section{In genetical terms: monogenic vs. oligo-/polygenic}

\section{Frequency (\%)}

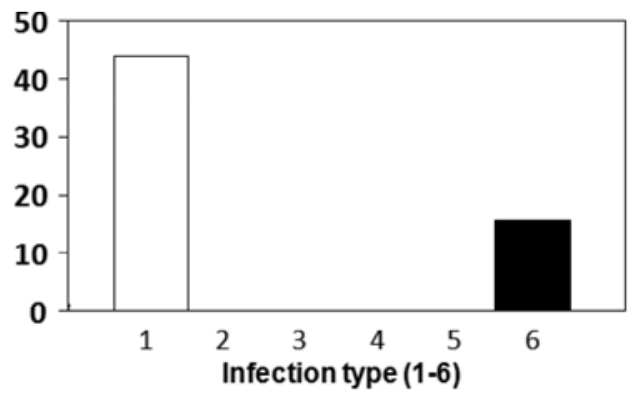

\section{Frequency $(\%)$}

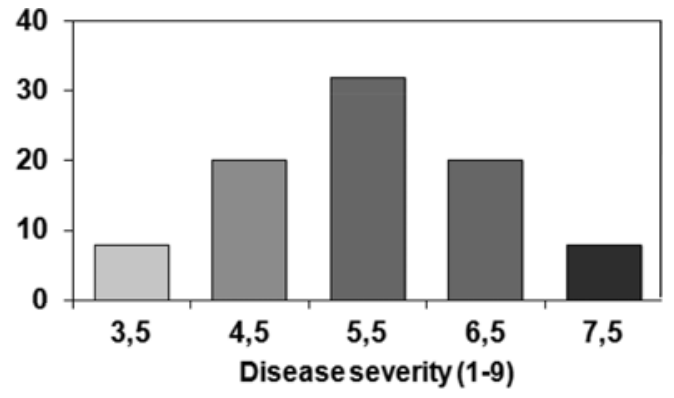


in this context that individual disease resistances alone are not an argument for releasing a variety. A combination of precise phenotypic and marker data with the use of more sophisticated statistical models will be essential for the further implementation of MAS in practical breeding.

\section{POSITIVE EXAMPLES OF MAS IN PRACTICAL BREEDING PROGRAMS}

Compared with the huge number of marker studies published during the last decades, the use of these markers in selection programs by practical plant breeders has been insufficient and disappointing as stated by $\mathrm{Xu}$ and Crouch (41). The authors identified four areas in which MAS should be successful: (i) traits that are difficult to manage through conventional phenotypic selection because they are expensive or time-consuming to measure, have low penetrance or complex inheritance; (ii) traits whose selection depends on specific environments or host developmental stages; (iii) maintenance of recessive alleles during backcrossing or for speeding up backcross breeding in general; and (iv) pyramiding multiple monogenic traits or several QTL for a single disease resistance with complex inheritance. Additionally, molecular markers are a perfect tool for genetic studies, especially for evaluating the genetic architecture of a trait and to detect covariation among agronomically valuable traits, e.g., between disease resistance genes/QTLs and those for heading date or plant height. It might be helpful to look at some selected examples in which markers were widely adopted by practical breeding programs to discern what is needed for the future.

Easy going and fast: Monogenically inherited resistance genes in wheat and barley. MAS is a straight-forward technique for implementing or pyramiding monogenic resistances into breeding material because it is easy to find closely linked markers. In publicly financed wheat breeding programs of the United States, Australia, Canada, and CIMMYT, about 50 genes have been suggested for MAS, including resistance genes to powdery mildew, leaf rust, stem rust, stripe rust, several rust resistances combined, Mycosphaerella (anamorph Septoria) tritici, Oculimacula yallundae, cereal cyst nematode resistance, hessian fly, different aphid species, Barley yellow dwarf virus, Wheat streak mosaic virus, and Soilborne cereal mosaic virus $(9,14)$. A similar number of resistance genes is available in barley to leaf rust, powdery mildew, Rhynchosporium secalis, Pyrenophora teres f. teres, Barley yellow dwarf virus, and Barley yellow mosaic virus complex (7). For most of these genes, robust markers and laboratory protocols are available, but it is not clear from literature how wide they are really used in practical breeding. According to a British service lab (http://www.mrsltd.com/molecular.asp), molecular markers are used in barley for detection of rym4/rym5 against the Barley yellow mosaic virus complex in more than 10

\section{BOX 3}

Markers and marker techniques

\begin{tabular}{|c|c|}
\hline Allele mining & $\begin{array}{l}\text { Identification and access to allelic variation of a sequenced gene that affects the plant phenotype. } \\
\text { The DNA sequence or parts of it are used for searching new allelic variants of the same } \\
\text { (resistance) gene. }\end{array}$ \\
\hline Diagnostic marker & $\begin{array}{l}\text { Markers that could be used in multiple genetic backgrounds, ideally the marker-trait association is } \\
\text { valid in all germplasm. }\end{array}$ \\
\hline Genomic selection & $\begin{array}{l}\text { Selection based on genomic breeding values that are calculated as the sum of the effects of } \\
\text { dense genetic markers, or haplotypes of these markers, across the entire genome, thereby } \\
\text { potentially capturing all QTL that contribute to variation in a trait and similarly to multiple traits. }\end{array}$ \\
\hline MABC: marker-assisted backcrossing & $\begin{array}{l}\text { A molecular marker is used for indirect selection during backcrossing of the gene/QTL of interest } \\
\text { into elite material. }\end{array}$ \\
\hline Mapping & $\begin{array}{l}\text { Assigning markers, genes, and/or QTL in order, indicating the relative distances among them, and } \\
\text { assigning them to their linkage groups on the basis of their recombination values from all pairwise } \\
\text { combinations. }\end{array}$ \\
\hline Molecular marker & $\begin{array}{l}\text { Specific fragments of DNA with a known location on the chromosome that can be identified } \\
\text { within the whole genome and reveal neutral sites of variation. Markers that are in close linkage } \\
\text { with a particular gene/QTL of interest can be used for MAS. }\end{array}$ \\
\hline MAS: marker-assisted selection & $\begin{array}{l}\text { A marker (morphological, biochemical, or one based on DNA/RNA variation) is used for indirect } \\
\text { selection of a gene/QTL. }\end{array}$ \\
\hline Perfect marker & $\begin{array}{l}\text { A marker without recombination to the gene of interest, ideally drawn directly from the gene } \\
\text { sequence. }\end{array}$ \\
\hline QTL: quantitative trait locus/loci & $\begin{array}{l}\text { Location of a gene that affects a trait measured on a quantitative (linear) scale. QTL are identified } \\
\text { via statistical procedures that integrate genotypic and phenotypic data. }\end{array}$ \\
\hline SNP: single nucleotide polymorphism & $\begin{array}{l}\text { DNA sequence variation occurring when a single nucleotide in a shared sequence differs } \\
\text { between members of a biological species or paired chromosomes in an individual. }\end{array}$ \\
\hline SSR: single sequence repeat & $\begin{array}{l}\text { Also called microsatellite. It consists of a specific sequence of DNA nucleotides that contain } \\
\text { tandem repeats, e.g., GTGTGTGTGTGT would be referred to as }(G T)_{6} \text {. Alleles at a specific locus } \\
\text { can differ in the number of repeats. }\end{array}$ \\
\hline
\end{tabular}


breeding programs throughout Europe, of mlo powdery mildew resistance gene with the possibility to distinguish between the two main sources of the gene in commercial varieties, and of a gene for $R$. secalis. In wheat, clearly the Pchl gene counts as a gene which is routinely used in wheat breeding, similarly some of the rym genes in barley breeding. Still the access to diagnostic markers is often a problem. For most of the 13 major $S t b$ genes for resistance to $M$. graminicola (Septoria tritici; 13), for example, closely linked molecular markers are described in the literature, but with a few exceptions they are useful only in the mapping populations where they have been detected, but not in other elite breeding material (V. Korzun, personal communication). Furthermore, most of the known $S t b$ genes are ineffective against current pathogen populations (8).

In the past, many race-specific resistances of wheat and barley to powdery mildew (Blumeria graminis) and of wheat to yellow/ stripe rust (Puccinia striiformis) failed when introgressed alone or in pyramids into commercial cultivars. This was even true for genes like $\mathrm{Yrl1}, \mathrm{Yr} 13$, and $\mathrm{Yr} 14$ that express a partial resistance in adult plants (16). The question that arises is whether race-specific resistance genes at all are durable enough to be relied on. This is hard to answer because the durability of a resistance gene can only be judged after many years of widespread use in a region with frequent epidemics (16). However, based on about 5 decades of experience, resistance to biotrophs which relies on a hypersensitive response and is controlled by a single gene is very unlikely to be durable. It might be worthwhile to also select in these pathosystems for quantitative resistances, a strategy that was successful for powdery mildew in wheat cultivars (23), leaf rust in barley (Puccinia hordei; 28), and common rust in maize ( $P$. sorghi; 34). In these cases, commercial breeders did not rely on largely ineffective race-specific resistances, but gradually increased the level of quantitative resistance by recurrent selection. To avoid confounding effects with effective major genes segregating in the population, a seedling test should be applied firstly. Screening either with all effective virulences and virulence combinations present in the region or a highly virulent race would remove all major genes from the population that can afterwards be analyzed in the field for adult-plant resistance (28). It is, however, not possible to differentiate between polygenic quantitative resistance and race-specific adult-plant resistance without hypersensitivity response.

Only a few monogenically inherited fungal resistance genes are considered durable, e.g., mlo against powdery mildew in barley, rym4/rym5, a multi-allelic locus with resistance to Barley mild mosaic virus (BaMMV) and Barley yellow mosaic virus type 1 (BaYMV-1; 27), Lr34 conferring resistance to leaf rust, stripe rust, and powdery mildew (21), and Yr36 providing high-temperature dependent resistance with a partial effect to a broad spectrum of races of stripe rust (35). These genes have in the meantime been cloned $(5,10,19,33)$ and perfect markers directly drawn from the gene sequence are available. Another example of a monogenic, durable resistance gene is the Pchl gene governing resistance to strawbreaker or eyespot $(O$. yallundae). The genes Lr34, Yr36, and Pchl express a partially effective adult-plant resistance.

Recessive resistance genes and effective backcrossing: Barley/BaMMV, BaYMV. The BaYMV/BaMMV complex was previously known from Japan and first detected in Europe in 1978 in Germany and, since then, the viruses have spread over large acreages causing one of the most important diseases of winter barley today (27). Resistance sources are quite frequent in cultivated barley and several monogenic, recessive resistance genes (ryml to rym15) have been detected and mapped on five chromosomes (27). Today, rym4/rym5 is most widespread and was introgressed into elite populations using simple sequence repeat markers. In Germany, for example, 52 out of 62 released winter barley cultivars are resistant to the most widespread strains (3). MAS was the method of choice for introgression because (i) the resistance is recessive, (ii) the resistance to BaYMV cannot be screened on the single-plant level in the greenhouse, and (iii) pyramiding of several genes (rym5, rym9) is necessary (39) to confer resistance to all presently known virus strains. The rym4/ rym5 locus has been cloned recently and turned out to be the translation initiation factor 4E $(H v-e I F 4 E ; 33)$. Detailed analysis showed that specific SNPs confer resistance to different strains of both viruses, and rym4 and rym 5 are alleles with only seven SNPs out of 645 base pairs being different. Several new alleles of this resistance gene have been detected by resequencing about 1,000 entries of the Gatersleben gene bank (27), illustrating the power of allele mining once the gene sequence is available.

Stacking QTL with large and stable effects: Wheat/Fusarium head blight. Fusarium head blight (FHB) is a worldwide important disease mainly caused by Fusarium graminearum. Selection is tedious because the resistance is inherited oligo-/polygenically, is highly affected by genotype-by-environment interaction, and must be performed in artificially infected plots. The QTL Fhbl for FHB resistance is to date the only disease resistance QTL that is routinely used in wheat breeding, although since 1992 at least 331 QTL studies have been published on disease resistance in wheat according to an actual SCOPUS database search. Fhbl explained 20 to $40 \%$ of phenotypic variation in the mapping populations $(2,4,43)$ and was validated in diverse wheat backgrounds $(1,25,42)$. Today, it is widely used in the United States and Canada, for example in the U.S. cultivar Alsen $(11,22)$. A second QTL useful for MAS is Qfhs.ifa-5A on chromosome $5 \mathrm{~A}$, explaining $23 \%$ of phenotypic variation in the mapping population (4). Marker-based introgression of both QTL in independent, elite spring wheat lines resulted in QTL effects of $10 \%$ reduced FHB rating for each of Fhbl and the 5A QTL (25). These values are considerably less than those estimated in the original mapping populations but this is typical for QTL studies (36). Performing one cycle of recurrent selection with a spring wheat population where both QTL have been introgressed resulted in a mean realized response from selection of 3.2 versus $4.4 \%$ per year for the phenotypic versus marker variant, respectively (40). The main advantage of MAS was halving the cycle length of selection because crossing, selfing, and selection by MAS could be done in 2 years, whereas phenotypic selection needed 4 years due to the necessity of adult-plant testing in the field. From this study, it was suggested that the best way to use the full range of quantitative variation for resistance is to apply MAS followed by phenotypic selection. This procedure allows the incorporation of minor QTL which have been undetected in QTL mapping studies. The best progeny of this study had a similar resistance and similar low DON content in elite background as the resistant donor. In accordance with the findings of Salameh et al. (30), both QTL acted additively together independently of the genetic backgrounds. This underlines the interest in combining major QTL to increase the resistance level. Somers et al. (31) used a MAS program for introgressing six validated FHB resistance QTL, orange blossom midge resistance $(\mathrm{Sml})$ and leaf rust resistance (Lr21) into elite spring wheat during two backcrosses and two selfings within 25 months; however, it is not clear whether new varieties came from this program or selected lines have been used in prebreeding.

Marker-based backcrossing of the two QTL Fhbl and Qfhs.ifa$5 A$ in European elite winter wheat also resulted in a significant improvement of FHB resistance. Because of the very high yield of winter wheat in Germany, northern France, and the UK, breeders are extremely cautious to use nonadapted germplasm. In the marker class containing both QTL, grain yield of progeny was 
significantly reduced by $1.6 \%$ in one of the two backcross populations, the other population was not affected (38). Because no fine mapping of this QTL is available, it cannot be concluded whether the small yield penalty in one backcross population is due to pleiotropy or linkage drag. Entries with only one of either QTL showed no significantly different grain yield compared with the class without QTL in both backcross populations. Due to the significant phenotypic variation for FHB resistance and grain yield within each marker class, selection of lines with improved resistance and a high yield level similar to that in the recurrent parent should be feasible. For other agronomic and quality traits, differences were small in all cases, although often significant. Similar results were obtained by Salameh et al. (30), who stressed the effect of the recurrent parent on the final FHB resistance level after MABC. In conclusion, both resistance QTL are effective and stable in elite spring and winter wheat backgrounds and can be used for MAS without any known agronomical penalties.

This example nicely demonstrates the long time frame required from QTL mapping to the introgression of these QTL into practical breeding programs. In this case it was fortunate that (i) Fhbl is one of those QTL for disease resistance with the highest explained phenotypic variance found to date, (ii) the marker alleles linked to the resistance allele are not present in European and North American elite wheat, and (iii) near-perfect markers are available. The situation is much more complicated in pathosystems like wheat/M. graminicola where a high number of QTL with mainly low effects prevail $(6,29)$.

Recently, broad-spectrum resistance (BSR) QTL have been detected in wheat conferring quantitative resistance to multiple taxa of pathogens, e.g., on chromosomes 4D, 6D, and 7B for resistance to Septoria tritici blotch (STB) and FHB, on chromosome 4B for STB and Stagonospora nodorum blotch (SNB), and on chromosome 5B for SNB and FHB, all detected in the adultplant stage (24). Similarly, Zwart et al. (44) reported that a major QTL each for seedling resistance to STB and tan spot that were contributed by one parent and linked in repulsion with the coincident $\mathrm{Lr} 24 / \mathrm{Sr} 24$ locus carried by the other parent. Accordingly, the $L r 34 / Y r 18 / P m 38$ locus refers to a single gene that is effective against three biotrophic fungi (19). Such BSR QTL offer a good chance for improving multiple disease resistances by using just a few markers.

\section{WHAT IS NEXT?}

$\mathrm{Xu}$ and Crouch (41) highlighted the fact that despite a tremendous input in developing molecular markers during the last 20 years, only a few examples exist of registration of new cultivars resulting from MAS. This might be because monogenic traits that are easy to handle are not necessarily prone to marker application and vice versa, that most economically important traits are not accessible for MAS, because too many loci are involved with too small effects, a high impact of genotype-by-environment interaction and/or epistastic effects that hinder the use in each geographic region or genetic background.

This reticence toward the use of MAS in practical wheat and barley breeding might change in the next years by technological improvements. With the implementation of chip-based, highthroughput genotyping platforms, the cost of marker analysis will be less important. Whole genome array-based assays, like the $9 \mathrm{k}$ iSelect Infinium HD assays for wheat and barley (www.illumina. com), have just started to be used in breeders' labs, mainly focusing on marker discovery for specific traits of high economic importance. Once closely linked SNPs have been detected, several techniques allow the routine selection of favorable alleles in breeding populations (e.g., Illumina GoldenGate assay, KASP markers from KBioscience). The implementation of MAS for high-priority disease resistances will become routine work. The ultimate genotyping platform would be genotyping by sequencing, now becoming available for the first crops.

If genomic selection (15) will be successful in plant breeding, allelic variation at all known resistance loci in a crop will be selected in the future together with those for other agronomic traits all at once by medium- to high-density chips and the effectiveness of individual markers will not be restricting. Even if individual genes/QTL have only a low impact on disease resistance, they might help improve germplasm during several cycles of genomic selection. Then quantitative resistances could be handled easier and much more efficiently than nowadays. Genotypes with the desired combinations of alleles can be preselected before expensive field testing. However, until now only a few studies on genomic selection using single traits have been published, and for multistage selection with a lot of economically important traits, as necessary for wheat and barley breeding, still biometrical achievements have to be made and to be implemented in computer programs that are easy to use. Genetic constraints, like epistasis, linkage between wanted and unwanted QTL alleles or questions how to efficiently enhance genetic variation, will however stay a challenge for cultivar development. Another continuing task will be to make new effective resistance genes/alleles available for the well-known disease and for newly arising diseases caused by global climate change or intensified globalization. This will remain a challenge for phytopathologists and plant breeders.

\section{LITERATURE CITED}

1. Anderson, J. A., Chao, S., and Liu, S. 2007. Molecular breeding using a major QTL for Fusarium head blight resistance in wheat. Crop Sci. 47:112-119.

2. Anderson, J. A., Stack, R. W., Liu, S., Waldron, B. L., Fjeld, A. D., Coyne, C., Moreno-Sevilla, B., Fetch, J. M., Song, Q. J., Cregan, P. B., and Frohberg, R. C. 2001. DNA markers for Fusarium head blight resistance QTL in two wheat populations. Theor. Appl. Genet. 102:1164-1168.

3. Anonymous. 2011. Descriptive list of recommended cultivars. LandbuchVerlag, Hannover, Germany [In German: Beschreibende Sortenliste. Getreide, Mais, Öl-und Faserpflanzen, Leguminosen, Rüben, Zwischen früchte]. Online publication http://www.bundessortenamt.de/internet30/ index.php?id=164.

4. Buerstmayr, H., Steiner, B., Hartl, L., Griesser, M., Angerer, N., Lengauer, D., Miedaner, T., Schneider, B., and Lemmens, M. 2003. Molecular mapping of QTL for Fusarium head blight resistance in spring wheat. II. Resistance to fungal penetration and spread. Theor. Appl. Genet. 107:503-508.

5. Büschges, R., Hollricher, K., Panstruga, R., Simons, G., Wolter, M., Frijters, A., van Daelen, R., van der Lee, T., Diergaarde, P., Groenendijk, J., Töpsch, S., Vos, P., Salamini, F., and Schulze-Lefert, P. 1997. The barley mlo gene: A novel control element of plant pathogen resistance. Cell 88:695-705.

6. Chartrain, L., Brading, P. A., Widdowson, J. P., and Brown, J. K. M. 2004. Partial resistance to Septoria tritici blotch (Mycosphaerella graminicola) in wheat cultivars Arina and Riband. Phytopathology 94:497-504.

7. Chelkowski, J., Tyrka, M., and Sobkiewicz, A. 2003. Resistance genes in barley (Hordeum vulgare L.) and their identification with molecular markers. J. Appl. Genet. 44:291-309.

8. Cowger, C., Hoffer, M. E., and Mundt, C. C. 2000. Specific adaptation by Mycosphaerella graminicola to a resistant wheat cultivar. Plant Pathol. 49:445-451.

9. Dubcovsky, J. 2011. Marker-assisted selection in wheat. Published online by the USDA National Institute of Food and Agriculture. http:// maswheat.ucdavis.edu/.

10. Fu, D., Uauy, C., Distelfeld, A., Blechl, A., Epstein, L., Chen, X., Sela, H., Fahima, T., and Dubcovsky, J. 2009. A kinase-START gene confers temperature-dependent resistance to wheat stripe rust. Science 323:13571360.

11. Gamotin, E. L., Berzonsky, W. A., Ali, S., Adhikare, T., and Leach, G. D. 2007. Pyramiding different sources of Fusarium head blight resistance into spring wheat. Page 139 in: Proc. Plant Animal Genomes Conf. 15th, San Diego, CA. 
12. Geiger, H. H., and Heun, M. 1989. Genetics of quantitative resistance to fungal diseases. Annu. Rev. Phytopathol. 27:317-341.

13. Goodwin, S. B. 2007. Back to basics and beyond: Increasing the level of resistance to Septoria tritici blotch in wheat. Australas. Plant Pathol. 36:532-538.

14. Gupta, P. K., Langridge, P., and Mir, R. R. 2010. Marker-assisted wheat breeding: Present status and future possibilities. Mol. Breed. 26:145-161.

15. Heffner, E. L., Sorrells, M. R., and Jannink, J.-L. 2009. Genomic selection for crop improvement. Crop Sci. 49:1-12.

16. Johnson, R. 1992. Past, present and future opportunities in breeding for disease resistance, with examples from wheat. Euphytica 63:3-22.

17. Koebner, R. 2003. MAS in cereals: Green for maize, amber for rice, still red for wheat and barley. In: Proc. FAO workshop "Marker assisted selection: A fast track to increase genetic gain in plant and animal breeding?" Online publication. http://www.fao.org/Biotech/docs/ Koebner.pdf.

18. Kover, P. X., and Caicedo, A. L. 2001. The genetic architecture of disease resistance in plants and the maintenance of recombination by parasites: Invited review. Mol. Ecol. 10:1-16.

19. Krattinger, S. G., Lagudah, E. S., Spielmeyer, W., Singh, R. P., HuertaEspino, J., McFadden, H., Bossolini, E., Selter, L. L., and Keller, B. 2009. A putative $\mathrm{ABC}$ transporter confers durable resistance to multiple fungal pathogens in wheat. Science 323:1360-1363.

20. Kuchel, H., Ye, G., Fox, R., and Jefferies, S. 2005. Genetic and economic analysis of a targeted marker-assisted wheat breeding strategy. Mol. Breed. 16:67-78.

21. Lillemo, M., Asalf, B., Singh, R. P., Huerta-Espino, J., Chen, X. M., He, Z. H., and Bjørnstad, A. 2008. The adult plant rust resistance loci Lr34/Yr18 and Lr46/Yr29 are important determinants of partial resistance to powdery mildew in bread wheat line Saar. Theor. Appl. Genet. 116:1155-1166.

22. Mergoum, M., Frohberg, R. C., and Stack, R. W. 2007. Breeding hard red spring wheat for Fusarium head blight resistance, successes and challenges. Pages 161-167 in: Wheat Production in Stressed Environments. H. T. Buck, ed. Springer, the Netherlands.

23. Miedaner, T., and Flath, K. 2007. Effectiveness and environmental stability of quantitative powdery mildew (Blumeria graminis) resistance among winter wheat cultivars. Plant Breed. 126:553-558.

24. Miedaner, T., Risser, P., Paillard, S., Schnurbusch, T., Keller, B., Hartl, L., Holzapfel, J., Korzun V., Ebmeyer, E., and Utz, H. F. 2012. Broadspectrum resistance loci for three quantitatively inherited diseases in two winter wheat populations. Mol. Breed. 29:731-742.

25. Miedaner, T., Wilde, F., Steiner, B., Buerstmayr, H., Korzun, V., and Ebmeyer, E. 2006. Stacking quantitative trait loci (QTL) for Fusarium head blight resistance from non-adapted sources in an European elite spring wheat background and assessing their effects on deoxynivalenol (DON) content and disease severity. Theor. Appl. Genet. 112:562-569.

26. Niks, R. E., Parlevliet, J. E., Lindhout, P., and Bai, Y. 2011. Breeding Crops with Resistance to Diseases and Pests. Wageningen Academic Publishers, The Netherlands.

27. Ordon, F., Habekuss, A., Kastirr, U., Rabenstein, F., and Kühne, T. 2009. Virus resistance in cereals: Sources of resistance, genetics and breeding. J. Phytopathol. 157:535-545.

28. Parlevliet, J. E. 1995. Genetic and breeding aspects of durable resistance of crops to pathogens. African Crop Sci. J. 3:1-13. Online publication. http://www.ajol.info/index.php/acsj/article/viewFile/54555/43069.
29. Risser, P., Ebmeyer, E., Korzun, V., Hartl, L., and Miedaner, T. 2011. Quantitative-trait loci for adult-plant resistance to Septoria tritici in two large winter wheat populations. Phytopathology 101:1209-1216.

30. Salameh, A., Buerstmayr, M., Steiner, B., Neumayer, A., Lemmens, M., and Buerstmayr, H. 2010. Effects of introgression of two QTL for Fusarium head blight resistance from Asian spring wheat by markerassisted backcrossing into European winter wheat on Fusarium head blight resistance, yield and quality traits. Mol. Breed. 28:485-494.

31. Somers, D. J., Thomas, J., DePauw, R., Fox, S., Humphreys, G., and Fedak, G. 2005. Assembling complex genotypes to resist Fusarium in wheat (Triticum aestivum L.). Theor. Appl. Genet. 111:1623-1631.

32. Stam, P., and Zeven, A. C. 1981. The theoretical proportion of the donor genome in near-isogenic lines in self-fertilizers bred by backcrossing. Euphytica 30:227-238.

33. Stein, N., Perovic, D., Kumlehn, J., Pellio, B., Stracke, S., Streng, S., Ordon, F., and Graner, A. 2005. The eukaryotic translation initiation factor $4 \mathrm{E}$ confers multiallelic recessive Bymovirus resistance in Hordeum vulgare (L.). Plant J. 42:912-922.

34. Stuthman, D. D., Leonard, K. J., and Miller-Garvin, J. 2007. Breeding crops for durable resistance to disease. Adv. Agron. 95:319-367.

35. Uauy, C., Brevis, J. C., Chen, X., Khan, I., Jackson, L., Chicaiza, O., Distelfeld, A., Fahima, T., and Dubcovsky, J. 2005. High-temperature adult-plant (HTAP) stripe rust resistance gene Yr36 from Triticum turgidum ssp. dicoccoides is closely linked to the grain protein content locus $G p c-B 1$. Theor. Appl. Genet.112:97-105.

36. Utz, H. F., Melchinger, A. E., and Schön, C. C. 2000. Bias and sampling error of the estimated proportion of genotypic variance explained by quantitative trait loci determined from experimental data in maize using cross validation and validation with independent samples. Genetics 154:1839-1849.

37. Van der Plank, J. E. 1968. Disease Resistance in Plants. 2nd ed. Academic Press, New York/London.

38. Von der Ohe, C., Ebmeyer, E., Korzun, V., and Miedaner, T. 2010 Agronomic and quality performance of winter wheat backcross populations carrying non-adapted Fusarium head blight resistance QTL. Crop Sci. 50:2283-2290

39. Werner, K., Friedt, W., and Ordon, F. 2005. Strategies for pyramiding resistance genes against the barley yellow mosaic virus complex (BaMMV, BaYMV, BaYMV-2). Mol. Breed. 16:45-55.

40. Wilde, F., Korzun, V., Ebmeyer, E., Geiger, H. H., and Miedaner, T. 2007. Comparison of phenotypic and marker-based selection for Fusarium head blight resistance and DON content in spring wheat. Mol. Breed. 19:357370.

41. Xu, Y., and Crouch, J. H. 2008. Marker-assisted selection in plant breeding: From publications to practice. Crop Sci. 48:391-407.

42. Zhou, W. C., Kolb, F. L., Bai, G. H., Domier, L. L., Boze, L. K., and Smith, N. J. 2003. Validation of a major QTL for scab resistance with SSR markers and use of marker-assisted selection in wheat. Plant Breed. 122:40-46.

43. Zhou, W. C., Kolb, F. L., Bai, G. H., Domier, L. L., and Yao, J. B. 2002. Effect of individual Sumai3 chromosomes on resistance to scab spread within spikes and deoxynivalenol accumulation within kernels in wheat. Hereditas 137:81-89.

44. Zwart, R. S., Thompson, J. P., Milgate, A. W., Bansal, U. K., Williamson, P. M., Raman, H., and Bariana, H. S. 2010. QTL mapping of multiple foliar disease and root-lesion nematode resistances in wheat. Mol. Breed. 26:107-124. 